\title{
Unravelling the mechanism of photoinduced charge transfer processes in lead iodide perovskite solar cells
}

\author{
Arianna Marchioro, ${ }^{1,2}$, Joël Teuscher², Dennis Friedrich ${ }^{3}$, Marinus Kunst ${ }^{3}$, Roel van de Krol ${ }^{3}$, \\ Thomas Moehl ${ }^{2}$, Michael Grätzel ${ }^{2}$ and Jacques-E. Moser ${ }^{1 \star}$
}

Lead halide perovskites have recently been used as light absorbers in hybrid organic-inorganic solid-state solar cells, with efficiencies as high as $15 \%$ and open-circuit voltages of $1 \mathrm{~V}$. However, a detailed explanation of the mechanisms of operation within this photovoltaic system is still lacking. Here, we investigate the photoinduced charge transfer processes at the surface of the perovskite using time-resolved techniques. Transient laser spectroscopy and microwave photoconductivity measurements were applied to $\mathrm{TiO}_{2}$ and $\mathrm{Al}_{2} \mathrm{O}_{3}$ mesoporous films impregnated with $\mathrm{CH}_{3} \mathrm{NH}_{3} \mathrm{Pbl}_{3}$ perovskite and the organic hole-transporting material spiro-OMeTAD. We show that primary charge separation occurs at both junctions, with $\mathrm{TiO}_{2}$ and the hole-transporting material, simultaneously, with ultrafast electron and hole injection taking place from the photoexcited perovskite over similar timescales. Charge recombination is shown to be significantly slower on $\mathrm{TiO}_{2}$ than on $\mathrm{Al}_{2} \mathrm{O}_{3}$ films.

$\mathrm{H}$ ybrid organic-inorganic all-solid-state solar cells based on methylammonium lead halide perovskite absorbers are currently attracting increasing interest because of their ease of fabrication and performances rivalling the best thin-film photovoltaic devices ${ }^{1-7}$. Of the various types of perovskites and morphologies reported to date, $\mathrm{CH}_{3} \mathrm{NH}_{3} \mathrm{PbI}_{3}$ deposited on a mesoporous film of titanium dioxide through a sequential deposition method appears to yield the best certified conversion efficiency ${ }^{1}$. The optical and electronic properties of perovskite materials have been studied thoroughly in recent decades ${ }^{8-11}$. As hybrid organic-inorganic lead halide perovskites can cumulate functions of light absorption, n-type conduction ${ }^{6}$ and p-type conduction ${ }^{12}$, the current picture for the hybrid spiro-OMeTAD|perovskite $\mid \mathrm{TiO}_{2}$ cell could be described as follows (Fig. 1). The perovskite absorbs light and electron-hole pairs are created in the material, which can possibly evolve towards the formation of excitons after thermalization of the carriers. Charge separation can then occur through two possible primary reactions: injection of photogenerated electrons into $\mathrm{TiO}_{2}$ nanoparticles (equation (1a)) and/or injection of holes (equation (2a)) into a hole-transporting material (HTM) such as spiro$\mathrm{OMeTAD}^{2,13}$. However, which electron or hole injection process occurs first and, in the latter case, whether electron injection into and transport within the oxide mesoporous film (equation (2b)) is playing any role, remain unclear. The precise role of titanium dioxide in efficient perovskite solar cells based on mesoporous films of this particular metal oxide has indeed not been established clearly. Evidence has been found for electron injection from the mixed halide $\mathrm{CH}_{3} \mathrm{NH}_{3} \mathrm{PbI}_{2} \mathrm{Cl}$ into $\mathrm{TiO}_{2}$ (refs 6,14), and the same material has also been reported to yield efficient photovoltaic conversion once dispersed on an insulating alumina framework, in which electron injection is not energetically feasible and where no sensitization of the oxide material can be invoked ${ }^{6}$.
Electron injection as the primary charge separation step:

$$
\begin{gathered}
\left(\mathrm{e}^{-} \ldots \mathrm{h}^{+}\right)_{\text {perovskite }} \rightarrow \mathrm{e}_{\mathrm{cb}}{ }^{-}\left(\mathrm{TiO}_{2}\right)+\mathrm{h}^{+} \text {(perovskite) } \\
\left.\mathrm{h}^{+} \text {(perovskite }\right) \rightarrow \mathrm{h}^{+}(\mathrm{HTM})
\end{gathered}
$$

Hole injection as the primary charge separation step:

$$
\begin{gathered}
\left(\mathrm{e}^{-} \ldots \mathrm{h}^{+}\right)_{\text {perovskite }} \rightarrow \mathrm{h}^{+}(\mathrm{HTM})+\mathrm{e}^{-} \text {(perovskite) } \\
\left.\mathrm{e}^{-} \text {(perovskite }\right) \rightarrow \mathrm{e}_{\mathrm{cb}}^{-}\left(\mathrm{TiO}_{2}\right)
\end{gathered}
$$

Exciton annihilation:

$$
\begin{gathered}
\left(\mathrm{e}^{-} \ldots \mathrm{h}^{+}\right)_{\text {perovskite }} \rightarrow h v^{\prime} \\
\left(\mathrm{e}^{-} \ldots \mathrm{h}^{+}\right)_{\text {perovskite }} \rightarrow \nabla
\end{gathered}
$$

Back electron transfer at the $\mathrm{TiO}_{2}$ surface:

$$
e_{\mathrm{cb}}^{-}\left(\mathrm{TiO}_{2}\right)+\mathrm{h}^{+} \text {(perovskite) } \rightarrow \nabla
$$

Back charge transfer at the HTM surface:

$$
\mathrm{h}^{+}(\mathrm{HTM})+\mathrm{e}^{-}(\text {perovskite }) \rightarrow \nabla
$$

Charge recombination at the $\mathrm{TiO}_{2} \mid \mathrm{HTM}$ interface:

$$
\mathrm{e}_{\mathrm{cb}}{ }^{-}\left(\mathrm{TiO}_{2}\right)+\mathrm{h}^{+}(\mathrm{HTM}) \rightarrow \nabla
$$

Undesired reactions such as exciton annihilation, leading to

\footnotetext{
'Photochemical Dynamics Group, Institute of Chemical Sciences and Engineering, École Polytechnique Fédérale de Lausanne, CH-1015 Lausanne, Switzerland, ${ }^{2}$ Laboratory for Photonics and Interfaces, Institute of Chemical Sciences and Engineering, École Polytechnique Fédérale de Lausanne, $\mathrm{CH}-1015$ Lausanne, Switzerland, ${ }^{3}$ Institute for Solar Fuels, Helmholtz-Zentrum Berlin für Materialien und Energie GmbH, 14109 Berlin, Germany. *e-mail: je.moser@epfl.ch
} 


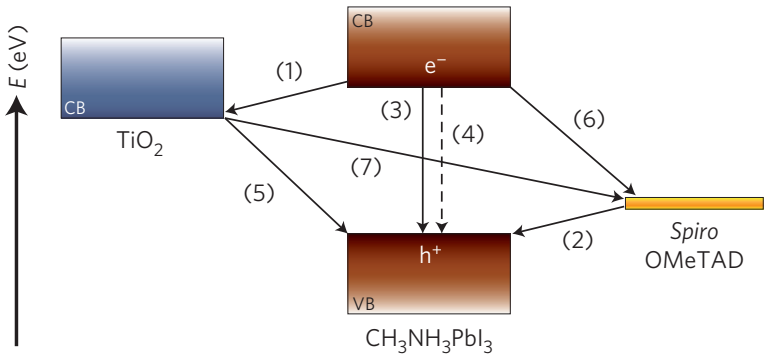

Figure 1 | Schematic diagram of energy levels and electron transfer processes in an $\mathrm{HTM} \mid$ perovskite $\mid \mathrm{TiO}_{2}$ cell.

photoluminescence (equation (3)) or to non-radiative recombination (equation (4)), as well as recombination of the charge carriers at the three interfaces (equations (5) to (7)) compete with the extraction of the photogenerated charges. The kinetics of these processes is thus expected to control, to a large extent, the overall photovoltaic conversion efficiency of the system.

In this work, we applied time-resolved spectroscopy techniques to assess the individual dynamics of all occurring interfacial photoinduced charge transfer processes and to derive the effective mechanism for charge separation. This information is of paramount importance for understanding the functioning of the devices and eventually for the improvement of their photovoltaic performances.

The dynamics of the various charge transfer processes were first assessed by probing optical transient absorption signals in the nearinfrared with $\mathrm{CH}_{3} \mathrm{NH}_{3} \mathrm{PbI}_{3}$ deposited on either mesoporous $\mathrm{TiO}_{2}$ or $\mathrm{Al}_{2} \mathrm{O}_{3}$ films, in the absence of HTM. To support and complement the mechanistic picture of the processes, time-resolved photoconductance measurements were also performed in the microwave frequency range. Because of the mismatch of the energies of the conduction bands of $\mathrm{Al}_{2} \mathrm{O}_{3}$ and the perovskite, electron injection is not thermodynamically feasible in this oxide. On alumina and in the absence of HTM, the only possible pathway for energy conservation after light absorption is electron-hole recombination, either through luminescence or non-radiative processes (equations (3) and (4)). Comparison with $\mathrm{TiO}_{2}$ samples thus provides evidence of electron injection (equation (1a)) and subsequent back charge transfer and recombination processes at the $\mathrm{TiO}_{2}$ surface (equations (5) and (7)) once the HTM is introduced into the system. A high power conversion efficiency of the photovoltaic device must obviously imply that the charge recombination processes (equations (3) to (7)) occur on a much slower timescale than the charge separation and extraction processes (equations (1) and (2)). It is therefore of crucial interest to determine the kinetics of these reactions so as to ultimately improve the cell's performance.

\section{Ultrafast transient optical absorption spectroscopy}

Femtosecond pump-probe transient absorption experiments were carried out at a probe wavelength of $1.4 \mu \mathrm{m}$ and an excitation wavelength of $580 \mathrm{~nm}$ for $\mathrm{CH}_{3} \mathrm{NH}_{3} \mathrm{PbI}_{3}$ samples deposited on $\mathrm{TiO}_{2}$ and $\mathrm{Al}_{2} \mathrm{O}_{3}$ films, with and without HTM. The resulting transient absorption was found in all cases to rise within the first picosecond (Fig. 2). The decay of the signal traces was observed to be multi-exponential for all samples and was fitted with a double exponential starting at $t=1 \mathrm{ps}$. The corresponding fast component developed within $40-60$ ps for all samples, while a slower component appeared in the $140-270$ ps time range. The $1.4 \mu \mathrm{m}$ probe wavelength was initially selected to probe oxidized spiro-OMeTAD, which absorbs in the near-infrared ${ }^{15,16}$. However, samples deprived of HTM yielded an important transient absorption signal originating from the perovskite itself. Comparing the signals obtained on the two different metal oxides, it is inferred that they reflect the time evolution of the

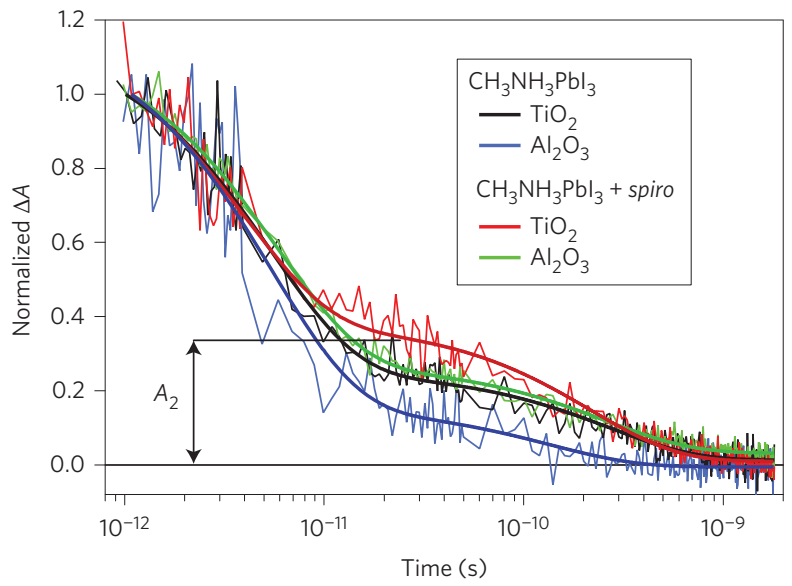

Figure 2 | Time evolution of electron and hole populations in photoexcited $\mathrm{CH}_{3} \mathrm{NH}_{3} \mathrm{Pbl}_{3}$ perovskite in various systems. Transient absorption signals were measured at a probe wavelength of $1.4 \mu \mathrm{m}$ following femtosecondlaser pulsed excitation at $580 \mathrm{~nm}: \mathrm{CH}_{3} \mathrm{NH}_{3} \mathrm{Pbl}_{3}$ on $\mathrm{TiO}_{2}$ (black); $\mathrm{CH}_{3} \mathrm{NH}_{3} \mathrm{Pbl}_{3}$ on $\mathrm{Al}_{2} \mathrm{O}_{3}$ (blue); $\mathrm{CH}_{3} \mathrm{NH}_{3} \mathrm{Pbl}_{3}$ and spiro-OMeTAD on $\mathrm{TiO}_{2}$ (red); $\mathrm{CH}_{3} \mathrm{NH}_{3} \mathrm{Pbl}_{3}$ and spiro-OMeTAD on $\mathrm{Al}_{2} \mathrm{O}_{3}$ (green). Thick solid lines represent bi-exponential fits of experimental points starting at $t=1 \mathrm{ps}$. $A_{2}$ represents the normalized absorbance change at $25 \mathrm{ps}$, used as a metric to compare the various samples.

$\mathrm{CH}_{3} \mathrm{NH}_{3} \mathrm{PbI}_{3}$ photoexcited states population. These excited states correspond to photogenerated electrons and holes, which can either be paired in excitons or exist in the form of free or even trapped charge carriers. In systems prepared on $\mathrm{TiO}_{2}$ films, a small contribution to the transient absorption signal of conduction-band electrons injected in $\mathrm{TiO}_{2}$ cannot be excluded. Similarly, for all systems containing spiro-OMeTAD HTM, contributions to the transient absorption signal of oxidized HTM species cannot be omitted and will be discussed later.

In the case of samples without HTM, a transient signal arising from the perovskite deposited on $\mathrm{Al}_{2} \mathrm{O}_{3}$ was observed and attributed to the decay of the carriers' population through recombination within the absorber material (blue trace, Fig. 2) as no interfacial reaction can take place in this case. Transient absorbance of a perovskite $\mid \mathrm{TiO}_{2}$ sample shows that the relative signal amplitude of the slower part, defined as the normalized absorbance change at $25 \mathrm{ps}$, is larger than on $\mathrm{Al}_{2} \mathrm{O}_{3}$ (Table 1, 24\% and $14 \%$, respectively). This relative signal amplitude is subsequently used as a metric to compare the various samples. We will assume in the following discussion that charge recombination within the perovskite is similar on $\mathrm{TiO}_{2}$ and $\mathrm{Al}_{2} \mathrm{O}_{3}$ samples. This assumption is corroborated by the observation from transient photoconductance (TPC) measurements (Fig. 3) that the charge decay within the perovskite is not influenced by deposition on a mesoporous framework with respect to perovskite deposited as a flat film on glass. For reasons that will be discussed in the following, the contribution to the transient absorption signal of electrons injected in the $\mathrm{TiO}_{2}$ conduction band is believed to be negligible. From this perspective, the larger

\section{Table 1 | Ratio of amplitude $A_{2}$ relative to the total normalized amplitude $\Delta A_{0}$ for $\mathrm{CH}_{3} \mathrm{NH}_{3} \mathrm{Pbl}_{3}$ on $\mathrm{TiO}_{2}$ and $\mathrm{Al}_{2} \mathrm{O}_{3}$, with and without spiro-OMeTAD HTM.}

\begin{tabular}{lll}
$\boldsymbol{A}_{2} / \Delta \boldsymbol{A}_{0}{ }^{\star}$ & Without HTM & With HTM \\
\hline $\mathrm{TiO}_{2}$ & 0.24 & 0.34 \\
$\mathrm{Al}_{2} \mathrm{O}_{3}$ & 0.14 & 0.26 \\
\hline
\end{tabular}

${ }^{\star} A_{2}$ measured from data displayed in Fig. 2 at $t=25 \mathrm{ps} ; \Delta A_{0}$ at $1 \mathrm{ps}$. 


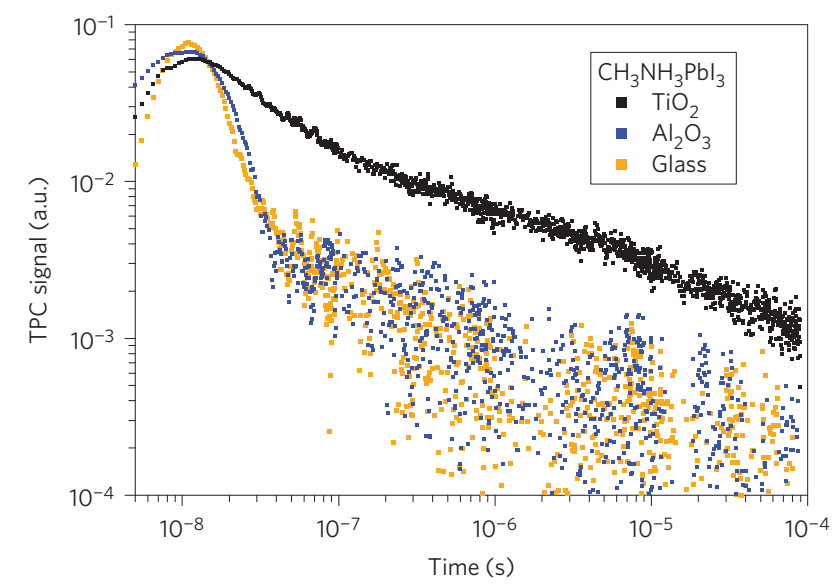

Figure 3 | Transient microwave photoconductance measurements of the perovskite material deposited on various substrates. $\mathrm{CH}_{3} \mathrm{NH}_{3} \mathrm{Pbl}_{3}$ on mesoporous $\mathrm{TiO}_{2}$ (black); $\mathrm{CH}_{3} \mathrm{NH}_{3} \mathrm{Pbl}_{3}$ on mesoporous $\mathrm{Al}_{2} \mathrm{O}_{3}$ (blue); $\mathrm{CH}_{3} \mathrm{NH}_{3} \mathrm{Pbl}_{3}$ on flat glass (orange). The build-up rate of the TPC signal is limited here by the excitation laser pulse duration ( $10 \mathrm{~ns}$ ).

relative amplitude for the slower part of the decay observed for the perovskite in contact with $\mathrm{TiO}_{2}$ indicates that some of the charges have already been separated through ultrafast electron injection (equation (1a)). The latter process leaves an excess of holes in the perovskite that take longer to recombine with the remaining electrons, whose population has been depleted. As the decay curves for the $\mathrm{TiO}_{2}$ case begin lagging behind that for $\mathrm{Al}_{2} \mathrm{O}_{3}$ at delay times $\geq 3$ ps (Fig. 2, black and blue curves, respectively), it is inferred that charge separation must occur at the perovskite|titania junction on a similar or shorter timescale.

Pairs of samples prepared on $\mathrm{Al}_{2} \mathrm{O}_{3}$ and $\mathrm{TiO}_{2}$ films were also measured with spiro-OMeTAD impregnating the mesoporous oxides. Interestingly, for a sample of $\mathrm{Al}_{2} \mathrm{O}_{3}$ with $\mathrm{HTM}$, the relative amount of remaining charges at a delay time of $25 \mathrm{ps}$ is similar to that observed for the previously discussed sample prepared on $\mathrm{TiO}_{2}$ and without spiro-OMeTAD (Table 1, 26\% relative amplitude). This indicates that hole injection into the HTM (equation (2a)) must be completed within a comparable timescale as electron injection into $\mathrm{TiO}_{2}$ (equation (1a)). In the case of perovskite in contact with both $\mathrm{TiO}_{2}$ and the HTM, the amount of longer-lived charges is higher (Table $1,34 \%$ relative amplitude). This result shows that the most efficient charge separation is obtained when using $\mathrm{TiO}_{2}$ and HTM together and is rationalized by the fact that the recombination of the remaining charges in the perovskite must account for charges that are injected at both separate junctions $\left(\mathrm{TiO}_{2}\right.$ |perovskite and perovskite|HTM). Here, in contrast to the case of perovskite deposited on $\mathrm{Al}_{2} \mathrm{O}_{3}$ and in contact with the HTM, no residual absorption is observable on the nanosecond timescale, as every carrier in the perovskite should have found an opposite charge with which to recombine. It could be argued that the longlived absorption actually results from the contribution of oxidized spiro-OMeTAD molecules- $\mathrm{h}^{+}(\mathrm{HTM})$ - as well as that of conduction-band electrons in $\mathrm{TiO}_{2}$, as both species absorb at $1.4 \mu \mathrm{m}$ (refs 15-17). However, this would not affect the reasoning above, as it would also provide direct evidence of charges having been separated at the junctions. Yet, we believe that these contributions are negligible in our measurements. Indeed, the reactions of $\mathrm{e}_{\mathrm{cb}}{ }^{-}$ $\left(\mathrm{TiO}_{2}\right)$ or $\mathrm{h}^{+}(\mathrm{HTM})$ recombining with carriers in the perovskite (equations (5) and (6)) are likely to take longer than a nanosecond (we show hereafter that the second reaction actually occurs over a microsecond timescale) and thus would appear as a long-lived plateau in the dynamics of the $\mathrm{TiO}_{2}+\mathrm{HTM}$ sample. This is not observed in this case.
Time-resolved microwave photoconductance measurements As a complementary technique, we used TPC measurements in the microwave frequency range to monitor directly the mobile charge carrier population within the perovskite material. The effect of electron injection from the perovskite into the mesoporous $\mathrm{TiO}_{2}$ and the resulting increase in charge carrier lifetime were observed with a time resolution of 10 ns (Fig. 3). No TPC signal was detected for pure $\mathrm{TiO}_{2}$ or $\mathrm{Al}_{2} \mathrm{O}_{3}$ films at the light intensities and excitation wavelength $(532 \mathrm{~nm})$ used in these experiments, showing that the observed photoconductance phenomena are induced only by photon absorption in the perovskite. As a result of charge separation or exciton splitting, an increase in the lifetime of the separated charge carriers can normally be observed. For the case with perovskite deposited on $\mathrm{Al}_{2} \mathrm{O}_{3}$ without any HTM present, one can expect the degradation of the absorbed photon energy by luminescence or thermalization. This can be clearly seen in Fig. 3, where no significant difference between a pure perovskite film on glass and perovskite deposited on $\mathrm{Al}_{2} \mathrm{O}_{3}$ can be observed. In the case where the perovskite is deposited on $\mathrm{TiO}_{2}$, an extension of the decay time is observed, indicating separation of the electron-hole pair and therefore the injection of electrons into titanium dioxide.

\section{Nanosecond transient optical absorption spectroscopy}

Flash photolysis experiments were carried out over an extended microsecond-to-millisecond time domain at a probe wavelength of $1.4 \mu \mathrm{m}$ and an excitation wavelength of $580 \mathrm{~nm}$, similarly to the femtosecond experiments. The expected transient signal in the microsecond timescale results from the absorption of the oxidized form of the spiro-OMeTAD- ${ }^{+}$(HTM)-. Indeed, spectral overlap with charge absorption of the perovskite could be avoided at this wavelength, as the decay of these charges should be completed much earlier within the nanosecond time span. This is confirmed by transient absorption, which shows no signal in the microsecond domain for $\mathrm{CH}_{3} \mathrm{NH}_{3} \mathrm{PbI}_{3}$ samples without HTM, either on $\mathrm{TiO}_{2}$ or $\mathrm{Al}_{2} \mathrm{O}_{3}$ (Fig. 4a). Although we expected to observe a transient signal corresponding to conduction-band electrons in the $\mathrm{TiO}_{2}$ that do absorb at this wavelength, this contribution to the signal appears to be buried in noise in this particular experiment. The time evolution of transient absorbance signals at $1.4 \mu \mathrm{m}$ for $\mathrm{CH}_{3} \mathrm{NH}_{3} \mathrm{PbI}_{3}$ samples with HTM (Fig. 4b) on $\mathrm{TiO}_{2}$ and on $\mathrm{Al}_{2} \mathrm{O}_{3}$ can, therefore, be assigned to the decay of the oxidized spiroOMeTAD population through recombination processes. On $\mathrm{Al}_{2} \mathrm{O}_{3}$, we observe recombination between $\mathrm{h}^{+}(\mathrm{HTM})$ and $\mathrm{e}^{-}$ (perovskite) (equation (6)), while on $\mathrm{TiO}_{2}$, recombination occurs between $\mathrm{h}^{+}(\mathrm{HTM})$ and $\mathrm{e}_{\mathrm{cb}}^{-}\left(\mathrm{TiO}_{2}\right)$ (equation (7)). The signal trace decay could be fitted with a stretched exponential (stretching exponent $\beta=0.5$ ). Excitation energy fluence in this particular experiment being rather low $\left(70 \mu \mathrm{J} \mathrm{cm}^{-2}\right.$, corresponding to $\sim 40$ photons per nanoparticle), the stretched exponential reflects a broad distribution of distances between the recombining charges. The difference between the time constants for the decay on $\mathrm{TiO}_{2}$ and $\mathrm{Al}_{2} \mathrm{O}_{3}$ is quite evident, and shows that recombination is slower when $\mathrm{TiO}_{2}$ is used ( $99 \mu$ s versus $15 \mu$ s on $\mathrm{Al}_{2} \mathrm{O}_{3}$ ). This demonstrates that process (6) is faster than process (7). It therefore provides additional evidence that electron injection has taken place and that recombination occurs via a mechanism that involves diffusion of carriers over a larger distance.

\section{Discussion}

The intrinsic physical properties of the perovskite material, such as exciton diffusion length, carrier mobility, nature and density of trap states, and the energetics of the bands, are obviously important in explaining why this exceptional material appears to be working in a variety of configurations. Rather than dealing with the intrinsic properties of the perovskite semiconductor, the 

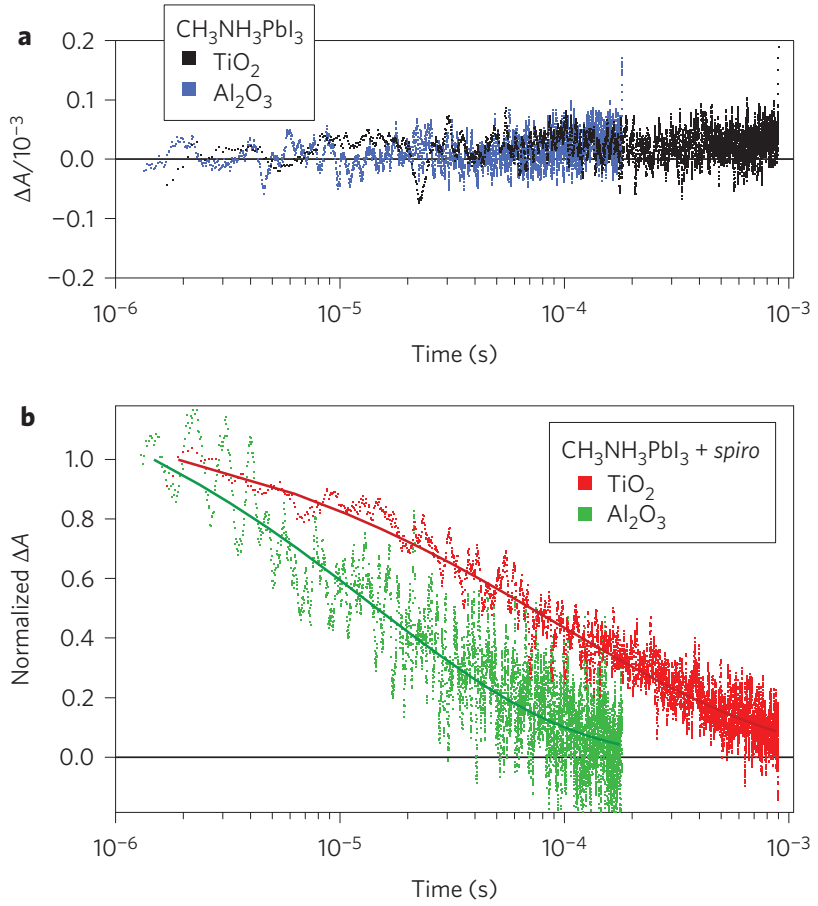

Figure 4 | Charge recombination dynamics obtained from nanosecondlaser flash photolysis of the various systems. Transient absorption signals were monitored at $\lambda=1.4 \mu \mathrm{m}$ following excitation at $580 \mathrm{~nm}$. a, Samples without $\mathrm{HTM}: \mathrm{CH}_{3} \mathrm{NH}_{3} \mathrm{Pbl}_{3}$ on $\mathrm{TiO}_{2}$ (black); $\mathrm{CH}_{3} \mathrm{NH}_{3} \mathrm{Pbl}_{3}$ on $\mathrm{Al}_{2} \mathrm{O}_{3}$ (blue) b, Samples with HTM. Signals mainly reflect the decay of the $\mathrm{h}^{+}(\mathrm{HTM})$ population. $\mathrm{CH}_{3} \mathrm{NH}_{3} \mathrm{Pbl}_{3}$ and spiro-OMeTAD on $\mathrm{TiO}_{2}$ (red); $\mathrm{CH}_{3} \mathrm{NH}_{3} \mathrm{Pbl}_{3}$ and spiro-OMeTAD on $\mathrm{Al}_{2} \mathrm{O}_{3}$ (green). Thick lines represent stretched exponential fit of data.

present work focuses on interfacial charge transfer processes occurring at the junctions between the light absorber and the electron- and/or hole-conducting materials. A sequence of interfacial electron transfer steps is derived from the kinetics determined experimentally in configurations that have already been proven to function efficiently in solar cells. We can then take for granted that the exciton diffusion length and carrier mobility within the perovskite are easily sufficient and that all energy levels are conveniently aligned ${ }^{18,19}$.

In samples containing the perovskite absorber deposited on a titanium dioxide electron acceptor with HTM infiltrating into the pores of the mesoscopic film, non-ideal morphologies obtained during the preparation will lead to various local situations within the same sample, where perovskite domains could be insulated, in contact with only $\mathrm{TiO}_{2}$ or the HTM, or form two junctions with both the $\mathrm{TiO}_{2}$ and the HTM. All these different scenarios are encountered in current solar energy conversion devices of various architectures. Interest in discussions about the charge transfer mechanism taking place in $\mathrm{TiO}_{2}$ |perovskite|spiro-OMeTAD solidstate solar cells therefore extends beyond this particular example to other types of perovskite-based photovoltaic systems.

Four different cases related to the morphology of the sample could coexist in perovskite-based devices:

(1) All the perovskite is conformally deposited on top of the metal oxide (either the insulating $\mathrm{Al}_{2} \mathrm{O}_{3}$ or the $\mathrm{TiO}_{2}$ electron acceptor) as a thin light-harvesting film, with a thickness of at most a few nanometres.

(2) Part of the perovskite is not in direct contact with the oxide substrate but is present in the form of isolated crystalline domains in the pores and/or a capping layer on top of the mesoporous network.
All perovskite-based devices deposited on a mesoporous structure, regardless of preparation type, should fall into one of the two categories (1) or (2). When adding an HTM, these cases can be coupled with two additional cases in relation to the junction:

(3) All the HTM is conformally deposited into the pores, forming a continuous junction with the perovskite material.

(4) Not enough HTM is present in the pores, or the interfacial contact between the perovskite and the HTM is only partial as a result of infiltration problems.

We will rationalize, for each case, what could be observed by time-resolved laser spectroscopy, keeping in mind the possible influence of the contact at the various heterojunctions. In case (1), the intimate contact between the two semiconductors allows the electron injection process to be resolved unequivocally by a direct comparison between $\mathrm{TiO}_{2}$ - and $\mathrm{Al}_{2} \mathrm{O}_{3}$-based samples. In case (2), a capping layer of perovskite that is not in direct contact with the mesoporous oxide can be found and optical features of isolated perovskite material could be observed. In the specific case of $\mathrm{TiO}_{2}$, where we expect electron injection to take place, the presence of a capping layer would result in strong light absorption within this layer and consequently poor quenching by $\mathrm{TiO}_{2}$ due to lack of a good $\mathrm{TiO}_{2}$ |perovskite interface. Consequently, strong photoluminescence will be observed. In the absence of a good intimate contact with $\mathrm{TiO}_{2}$, the device can still work, with the perovskite playing the role of the electron-transporting material, as in the so-called meso-superstructured cells built on an insulating $\mathrm{Al}_{2} \mathrm{O}_{3}$ framework ${ }^{6}$. In case (3), a hole is easily extracted at the perovskite|HTM interface, according to measurements already reported $^{5}$, where the spiro-OMeTAD was shown to very efficiently quench perovskite's photoluminescence within a sub-picosecond time frame. In case (4), the absence of intimate contact between the light absorber and spiro-OMeTAD is likely to lead to a situation where the device resembles a p-type perovskite cell, where the $\mathrm{CH}_{3} \mathrm{NH}_{3} \mathrm{PbI}_{3}$ works as the hole-transporting material ${ }^{12}$. For a perovskite|HTM bilayer, in which holes have to diffuse across a 65-nm-thick absorber layer to reach the HTM junction, the extraction time extends to the picosecond-to-nanosecond timescale, much longer than for case (3) ${ }^{19}$. Case (4) will often occur in type (2) samples, because a capping layer of perovskite tends to prevent good infiltration of the HTM into the pores. Deposition of spiroOMeTAD on a case (1) sample will, in contrast, favour case (3), resulting in an optimal device ${ }^{1}$.

Part of the charge recombination observed in $\mathrm{TiO}_{2}$ |perovskite|spiro-OMeTAD samples can still occur from electrons in the perovskite (equation (6)) if they have not been injected efficiently into the $\mathrm{TiO}_{2}$. This would be the case if there were insufficient contact between the $\mathrm{TiO}_{2}$ and the perovskite-case (2). The time constant measured by flash photolysis experiments for a $\mathrm{TiO}_{2}+\mathrm{HTM}$ sample thus might include contributions from the recombination reactions (equations (6) and (7)).

The time-resolved measurements reported in the present work highlight, for the first time, some of the important processes in $\mathrm{CH}_{3} \mathrm{NH}_{3} \mathrm{PbI}_{3}$-sensitized samples and corresponding samples built on an $\mathrm{Al}_{2} \mathrm{O}_{3}$ scaffold. Probing in the near-infrared provides a way to circumvent spectral overlap arising from different types of morphological issue-case (1) or (2) - by observing only the carriers' population decay inside the perovskite itself rather than in the bulk luminescence that constitutes the main spectral feature observed in the visible range. In previous work by Kim and colleagues ${ }^{5}$, electron injection could not be demonstrated by monitoring the stimulated emission of the perovskite, most likely because the observed transient was originating from a capping layer of the material. The method originally used in this work to produce the samples consisted in spin-coating a mixed solution of $\mathrm{CH}_{3} \mathrm{NH}_{3} \mathrm{I}$ 
and $\mathrm{PbI}_{2}$ in gamma-butyrolactone $\mathrm{e}^{5}$. This has now been replaced by a sequential deposition method yielding more conformal films ${ }^{1}$. Near-infrared optical probing, which monitors the decay of the population of charges remaining in the photoexcited perovskite, is key in demonstrating charge separation processes taking place through both electron and hole injection.

Comparable kinetics for the decay of the remaining recombining charges in the perovskite $\mid \mathrm{TiO}_{2}$ and spiro-OMeTAD $\mid$ perovskite $\mid \mathrm{Al}_{2} \mathrm{O}_{3}$ samples indicate that electron and hole injection occur on similar timescales. Furthermore, it is possible to conclude that both charge separation processes happen on a femtosecond-to-picosecond timescale, as our previous study showed that hole injection, observed through stimulated emission quenching, has already taken place within the first picosecond following excitation ${ }^{5}$. Direct monitoring of the dynamics of primary charge separation is beyond the scope of this study.

The efficiency of charge extraction in a perovskite solar cell depends on the ratio between the rate constants for charge recombination and charge separation. It is thus important to determine the timescale for charge recombination processes in the cell. Results obtained by flash photolysis show that the recombination reaction for electrons and oxidized spiro-OMeTAD (equations (6) and (7)) is slow, taking place in the microsecond range. This indicates a factor of at least $10^{6}$ between charge separation and recombination rate constants at the HTM interface, ensuring a quantitative yield for sustained charge separation. Additionally, reaction (7), being slower than reaction (6), proves that the use of $\mathrm{TiO}_{2}$ as electron acceptor and transporter in conjunction with an organic HTM in contact with the perovskite is indeed quite beneficial.

\section{Conclusion}

Time-resolved techniques were applied to $\mathrm{CH}_{3} \mathrm{NH}_{3} \mathrm{PbI}_{3}$ deposited as a conformal film on $\mathrm{TiO}_{2}$ and $\mathrm{Al}_{2} \mathrm{O}_{3}$ samples to study the kinetics of interfacial electron transfer processes. Using ultrafast spectroscopy in the near-infrared, we were able to monitor transient absorption by photogenerated charges in the perovskite. The results showed that the decay of the charge population is delayed upon infiltration with the hole-transporting material spiroOMeTAD, which is consistent with previous evidence of primary hole injection from the photoexcited perovskite into the HTM. Moreover, evidence for electron injection from $\mathrm{CH}_{3} \mathrm{NH}_{3} \mathrm{PbI}_{3}$ into the $\mathrm{TiO}_{2}$ film was found. The latter process appears to occur over a similar timescale as hole injection. Further evidence was provided by TPC measurements, with a slower charge decay in the presence of $\mathrm{TiO}_{2}$ found in the microwave frequency range. Additionally, transient absorbance decay of oxidized spiroOMeTAD was monitored in the near-infrared. Experimental data showed that charge recombination with oxidized HTM species, which occurs over a microsecond timescale, is delayed on $\mathrm{TiO}_{2}$ films with respect to $\mathrm{Al}_{2} \mathrm{O}_{3}$, indicating that the mechanism involves recombination of charges separated by a longer distance. The observation of charge separation and charge recombination reactions is closely related to the method of preparing the samples. Optical signals can be largely influenced by the presence of a capping layer of perovskite that is not conformally deposited on the mesoporous oxide film. Conformal coating of the $\mathrm{TiO}_{2}$ surface with $\mathrm{CH}_{3} \mathrm{NH}_{3} \mathrm{PbI}_{3}$ facilitates charge separation by ensuring direct electron injection into the oxide. These findings highlight the advantage of employing two heterojunctions with titanium dioxide and the HTM while using perovskite as a solid-state light absorber.

\section{Methods}

Sample preparation. For the preparation of substrate films, $\mathrm{TiO}_{2}$ and $\mathrm{Al}_{2} \mathrm{O}_{3}$ pastes were chosen that had porosities and particle sizes as similar to each other as possible. A commercial $\mathrm{TiO}_{2}$ paste (Dyesol $18 \mathrm{NR}-\mathrm{T}, 18 \mathrm{~nm}$ average nanoparticle diameter) was used, diluted 1:3 (wt) in EtOH, yielding mesoporous films with an average pore size of $24 \mathrm{~nm}$. A home-made $\mathrm{Al}_{2} \mathrm{O}_{3}$ paste (17 nm average nanoparticle diameter) was used diluted 1:3 (wt) in EtOH, yielding films with an average pore size of $32 \mathrm{~nm}$.

The $\mathrm{TiO}_{2}$ and $\mathrm{Al}_{2} \mathrm{O}_{3}$ pastes $(100 \mu \mathrm{l})$ were spin-coated on $2 \times 2 \mathrm{~cm}$ glass microscope slides (5,000 r.p.m.,1,000 r.p.m. $\mathrm{s}^{-1}, 30 \mathrm{~s}$ ). The films were then dried for $15 \mathrm{~min}$ at $100{ }^{\circ} \mathrm{C}$ and sintered for $30 \mathrm{~min}$ at $500{ }^{\circ} \mathrm{C}$. These conditions yielded an average thickness of $400 \mathrm{~nm}$ for the $\mathrm{TiO}_{2}$ and $270 \mathrm{~nm}$ for the $\mathrm{Al}_{2} \mathrm{O}_{3}$ films, as measured by atomic force microscopy (Asylum Research Chypher).

$\mathrm{PbI}_{2}$ (99\%, Sigma-Aldrich) was dissolved in dimethylformamide at $70{ }^{\circ} \mathrm{C}$ to yield a concentration of $1 \mathrm{M}$. The $\mathrm{PbI}_{2}$ solution $(100 \mu \mathrm{l})$ was spin-coated on the mesoporous substrates (6,500 r.p.m., 5,500 r.p.m. $\mathrm{s}^{-1}, 30$ s). The films were then dried for $15 \mathrm{~min}$ at $70{ }^{\circ} \mathrm{C}$. Methylammonium iodide was synthesized according to a reported procedure $\mathrm{r}^{7}$ and a solution of $20 \mathrm{mg} \mathrm{ml}^{-1}$ of $\mathrm{CH}_{3} \mathrm{NH}_{3} \mathrm{I}$ in isopropanol was prepared. $\mathrm{PbI}_{2}$ substrates were immersed in this solution for $1 \mathrm{~min} 40 \mathrm{~s}$, leading to a drastic colour change of the film from yellow to dark brown. The films were rinsed in isopropanol for $10 \mathrm{~s}$.

A solution of spiro-OMeTAD (Merck KGaA) was prepared by dissolving $90 \mathrm{mg}$ in $1 \mathrm{ml}$ chlorobenzene at $60{ }^{\circ} \mathrm{C}$. 4 -Tert-butylpyridine (tBP, Sigma-Aldrich; $8.75 \mu \mathrm{l}$ ) was added to the latter chlorobenzene solution to yield a concentration of $0.06 \mathrm{M}$ tBP. Lithium bis(trifluoromethylsulphonyl)imide (LiTFSI, Sigma-Aldrich; 17 mg) was predissolved in $100 \mu \mathrm{l}$ acetonitrile, and $18.75 \mu \mathrm{l}$ of this solution was added to the same chlorobenzene solution to yield a concentration of $0.011 \mathrm{M}$ LiTFSI. The spiro-OMeTAD solution $(80 \mu \mathrm{l})$ with $\mathrm{tBP}$ and LiTFSI added was deposited onto the perovskite films and allowed to infiltrate for $10 \mathrm{~s}$ to maximize the penetration of the HTM before spin-coating (4,000 r.p.m., 770 r.p.m. s $^{-1}, 30$ s). All spin-coating operations were carried out in a dry glovebox under an argon atmosphere. After preparation, samples were placed under vacuum for a few minutes, stored in the glovebox, and finally encased in a sealed cell containing argon to avoid contact with air and oxygen during measurements.

Nanosecond flash photolysis. Transmission-mode transient absorption spectroscopy experiments were conducted using a frequency-tripled, $Q$-switched $\mathrm{Nd}$ :YAG laser (Continuum, $20 \mathrm{~Hz}$ repetition rate) pumping an optical parametric oscillator (OPO-355, GWU). The output wavelength of the OPO was tuned at $\lambda_{\text {exc }}=580 \mathrm{~nm}$ ( $7 \mathrm{~ns}$ pulse duration) and attenuated to $70 \mu \mathrm{J} \mathrm{cm}^{-2}$. The continuous-wave probe light from a xenon arc lamp was passed through various optical elements, the sample and a monochromator $\left(\lambda_{\text {probe }}=1.4 \mu \mathrm{m}\right)$ before being detected by an InGaAs photodiode with $1 \mathrm{k} \Omega$ load (SM05PD5A, Thorlabs). Averaging over at least 2,000 laser shots was carried out. Dynamics were recorded over 10,000 points and a second-order Savitzky-Golay smoothing algorithm on 45 points was applied.

Femtosecond laser spectroscopy. Transient absorption spectra were recorded using femtosecond pump-probe spectroscopy. The pump beam $\left(\lambda_{\text {exc }}=580 \mathrm{~nm}\right)$ was generated by pumping a two-stage non-collinear optical parametric amplifier (NOPA) by the $778 \mathrm{~nm}$ output of an amplified Ti:sapphire laser system (ClarkMXR, CPA-2001), providing $150 \mathrm{fs}$ pulses at a repetition rate of $1 \mathrm{kHz}$. The probe beam $\left(\lambda_{\text {probe }}=1.4 \mu \mathrm{m}\right)$ was generated by a second OPA (Light Conversion, TOPAS model $4 / 800$ ) and used without any compression (pulse duration $\sim 150 \mathrm{fs}$ ). The change in transmittance of the sample, that is, the change in intensity of the probe beam, was measured by an InGaAs photodiode (New Focus, model Nirvana 2017) protected by cutoff filters to avoid any scattered light from the pump. The lowamplitude signal was extracted by a lock-in amplifier (SR-830, Stanford Research) referenced to the chopper. The pump energy at the sample was $360 \mathrm{~nJ} /$ pulse with a spot size diameter of $\sim 560 \mu \mathrm{m}$. Temporal overlap between the pump and probe pulses at the sample position was measured with a Kerr gating technique and gave a typical instrument response function of $180 \mathrm{fs}$.

Time-resolved microwave conductivity measurements. TPC measurements in the microwave frequency range were performed by using a Ka-band $(28.5-40 \mathrm{GHz})$ apparatus, as described previously ${ }^{20}$. Samples were excited by $10 \mathrm{~ns}$ (full-width at half-maximum) pulses of a frequency-doubled Q-switched Nd:YAG laser at a wavelength of $532 \mathrm{~nm}$ with a beam diameter of $\sim 1.6 \mathrm{~mm}$. The excitation intensity was adjusted by the use of calibrated filters and set to $1,200 \mu \mathrm{J} \mathrm{cm}{ }^{-2}$ for samples on mesoporous films, while $7 \mu \mathrm{J} \mathrm{cm}{ }^{-2}$ was used for samples deposited on glass, which contained more perovskite material.

Received 13 July 2013; accepted 17 December 2013; published online 19 January 2014

\section{References}

1. Burschka, J. et al. Sequential deposition as a route to high-performance perovskite-sensitized solar cells. Nature 499, 316-319 (2013).

2. Heo, J. H. et al. Efficient inorganic-organic hybrid heterojunction solar cells containing perovskite compound and polymeric hole conductors. Nature Photon. 7, 486-491 (2013).

3. Noh, J. H., Im, S. H., Heo, J. H., Mandal, T. N. \& Seok, S. I. Chemical management for colorful, efficient, and stable inorganic-organic hybrid nanostructured solar cells. Nano Lett. 13, 1764-1769 (2013). 
4. Qiu, J.et al. All-solid-state hybrid solar cells based on a new organometal halide perovskite sensitizer and one-dimensional $\mathrm{TiO}_{2}$ nanowire arrays. Nanoscale $\mathbf{5}$, 3245-3248 (2013).

5. Kim, H.-S. et al. Lead iodide perovskite sensitized all-solid-state submicron thin film mesoscopic solar cell with efficiency exceeding 9\%. Sci. Rep. 2, 591 (2012).

6. Lee, M. M., Teuscher, J., Miyasaka, T., Murakami, T. N. \& Snaith, H. J. Efficient hybrid solar cells based on meso-superstructured organometal halide perovskites. Science 338, 643-647 (2012).

7. Im, J.-H., Lee, C.-R., Lee, J.-W., Park, S.-W. \& Park, N.-G. 6.5\% efficient perovskite quantum-dot-sensitized solar cell. Nanoscale 3, 4088-4093 (2011).

8. Papavassiliou, G. C. Three- and low-dimensional inorganic semiconductors. Prog. Solid State Chem. 25, 125-270 (1997).

9. Ishihara, T. Optical properties of PbI-based perovskite structures. J. Lumin. 60, 269-274 (1994).

10. Mitzi, D. B. Templating and structural engineering in organic-inorganic perovskites. J. Chem. Soc. Dalton Trans. 1-12 (2001)

11. Stoumpos, C. C., Malliakas, C. D. \& Kanatzidis, M. G. Semiconducting tin and lead iodide perovskites with organic cations: phase transitions, high mobilities, and near-infrared photoluminescent properties. Inorg. Chem. 52, 9019-9038 (2013).

12. Etgar, L. et al. Mesoscopic $\mathrm{CH}_{3} \mathrm{NH}_{3} \mathrm{PbI}_{3} / \mathrm{TiO}_{2}$ heterojunction solar cells. J. Am. Chem. Soc. 134, 17396-17399 (2012).

13. Bi, D., Yang, L., Boschloo, G., Hagfeldt, A. \& Johansson, E. M. J. Effect of different hole transport materials on recombination in $\mathrm{CH}_{3} \mathrm{NH}_{3} \mathrm{PbI}_{3}$ perovskitesensitized mesoscopic solar cells. J. Phys. Chem. Lett. 4, 1532-1536 (2013).

14. Liu, M., Johnston, M. B. \& Snaith, H. J. Efficient planar heterojunction perovskite solar cells by vapour deposition. Nature 501, 395-398 (2013).

15. Snaith, H. J. et al. Charge collection and pore filling in solid-state dye-sensitized solar cells. Nanotechnology 19, 424003 (2008).

16. Olson, C., Veldman, D., Bakker, K. \& Lenzmann, F. Characterization of the pore filling of solid state dye sensitized solar cells with photoinduced absorption spectroscopy. Int. J. Photoenergy 2011, 513089 (2011).

17. Rothenberger, G., Fitzmaurice, D. \& Grätzel, M. Spectroscopy of conduction band electrons in transparent metal oxide semiconductor films: optical determination of the flatband potential of colloidal titanium dioxide films. J. Phys. Chem. 96, 5983-5986 (1992).
18. Stranks, S. D. et al. Electron-hole diffusion lengths exceeding 1 micrometer in an organometal trihalide perovskite absorber. Science 342, 341-344 (2013).

19. Xing, G. et al. Long-range balanced electron- and hole-transport lengths in organic-inorganic $\mathrm{CH}_{3} \mathrm{NH}_{3} \mathrm{PbI}_{3}$. Science 342, 344-347 (2013).

20. Friedrich, D. \& Kunst, M. Analysis of charge carrier kinetics in nanoporous systems by time resolved photoconductance measurements. J. Phys. Chem. C $115,16657-16663$ (2011).

\section{Acknowledgements}

Financial support was provided by the Swiss National Science Foundation and the NCCRMUST programme. M.G. and J.T. acknowledge the European Research Council (ERC) for an Advanced Research Grant (ARG no. 247404) funded under the 'Mesolight' project. A.M. and J.-E.M. thank J. Burschka, A. Dualeh, S. M. Zakeeruddin and C. Grätzel for discussions, P. Comte for the preparation of $\mathrm{Al}_{2} \mathrm{O}_{3}$ paste, $\mathrm{P}$. Gao for the preparation of $\mathrm{CH}_{3} \mathrm{NH}_{3} \mathrm{I}$, A. Devižis for help with near-infrared detection and A. Gasperini for atomic force microscopy measurements.

\section{Author contributions}

A.M. designed the experiments and prepared the samples. A.M. and J.T. carried out the laser experiments and analysed the data with J.-E.M. T.M. and D.F. designed the photoconductance experiments. D.F. performed the microwave experiments on the samples prepared by T.M. and analysed the data with the help of T.M., M.K. and R.vdK. A.M. prepared the manuscript with the help of J.T. and J.-E.M. J.-E.M. designed the femtosecond and nanosecond experimental spectroscopy tools, conceived the project and directed the work. All other authors discussed the results and commented on the manuscript.

\section{Additional information}

Reprints and permissions information is available online at www.nature.com/reprints. Correspondence and requests for materials should be addressed to J.-E.M.

\section{Competing financial interests}

The authors declare no competing financial interests. 